DOI: $10.21767 / 2471-304 X .100008$

\title{
A Focus on Respiratory Tract Infection as an Important Risk Factor in COPD
}

Received: November 03, 2015; Accepted: November 05, 2015; Published: November 09, 2015

Keywords: COPD, Exacerbations, Infection, Respiratory tract

\section{Abbrevation: COPD: Chronic Obstructive Pulmonary Disease}

Chronic Obstructive Pulmonary Disease (COPD) is a gradually progressive chronic disease that can be characterized by an unavoidable decline in respiratory function, exercise capacity, and health status. Globally more than 3 million people are killed every year due to COPD related complications and it is the fourth largest cause of death worldwide [1]. Exacerbations are events in the natural history of COPD when there is a marked increase in symptoms like dyspnoea, sputum volume, and purulence [2]. The exacerbations are of immense clinical significance as they have a long term effect on health status. There has always been difference in opinion while comparing asthma and COPD. While some clinicians believe that the two of them are similar disease, the others prefer to treat both as different. However, there are several clinical evidences in support the latter view [3-5].

There is a lack of significant data on the COPD morbidity and mortality in Asian populations, including India. However, a few significant studies have been conducted in India, which help us to understand aetiology of this disease, where there are around half a million deaths every year [2]. India contributes a significant and growing percentage of COPD mortality which is estimated to be amongst the highest in the world; i.e., more than 64. An important study, 'Indian Study of Asthma, Respiratory Symptoms and Chronic Bronchitis' (INSEARCH) that was conducted in 12 urban and 11 rural sites, reported the prevalence of chronic bronchitis to be $3.49 \%$ (4.29\%in males and $2.7 \%$ in females) in adults $>35$ years [6] COPD remains considerably under diagnosed and under treated in spite of the availability of national and international guidelines for its diagnosis. According to crude estimates there are 30 million COPD patients in India [7].

Several genetic and environmental factors are associated with the development of the disease. Biomass fuel exposure and smoking are the main factors associated with the development of the disease as well as its exacerbation. An acute exacerbation of COPD (AECOPD) causes considerable morbidity and reduces the quality of life in patients with COPD. There are several etiologic factors that alone or in combination cause AECOPD. Infection of the respiratory tract is amongst the major etiologic factor of AECOPD [1].

\section{Madhu Khanna', Latika Saxena ${ }^{1}$ and Stuti Gupta ${ }^{1}$ SN Gaur ${ }^{2}$}

1 Department of Microbiology (Virology), VP Chest Institute, University of Delhi, Delhi, India

2 Department of Respiratory Medicine, VP Chest Institute, University of Delhi, Delhi, India

\section{Corresponding author:}

Madhu Khanna

\section{madhukhanna@hotmail.com}

Dept. of Microbiology, VP Chest Institute, University of Delhi, Delhi-110007, India.

Tel: +91-11-27662605

Citation: Gupta S, Raju KRS, Mulukutla $S$, et al. Peritoneal Mast Cell Stabilization Potential of Ziziphus Xylopyrus (Retz) Wild Extract in Rat Mesenteric Model. Insights Allergy Asthma Bronchitis. 2015, 1:2.

Viral and bacterial infection of the respiratory tract may cause exacerbation. Other factors including chronic mucus hyper secretion, malnutrition, home care, socio-economic factor, education status, increasing age and co-morbidity may also play a role in COPD exacerbation $[8,9]$.

Several studies have established that coronavirus, influenza virus $A$ and $B$, parainfluenza virus, RSV (respiratory syncytium virus) (Figure 1), atypical organism like chlamydia, mycoplasma pneumonia were associated with exacerbations [10].In a recent study conducted in our laboratory, respiratory viruses were found in $70.9 \%$ of the patients with exacerbation of COPD. Bacterial infections were detected in $25.6 \%$ of the cases of exacerbations of COPD. Co-infection with more than one virus strain was also observed in some patients. In $19.5 \%$ of exacerbations were the cause was not infectious (under publication).

Respiratory viral infections, especially rhinoviruses were reported to be a major cause of COPD exacerbations, with upper respiratory tract infections in over $50 \%$ of COPD exacerbations. Virus infection was detected even in the stable patients, suggesting that chronic 


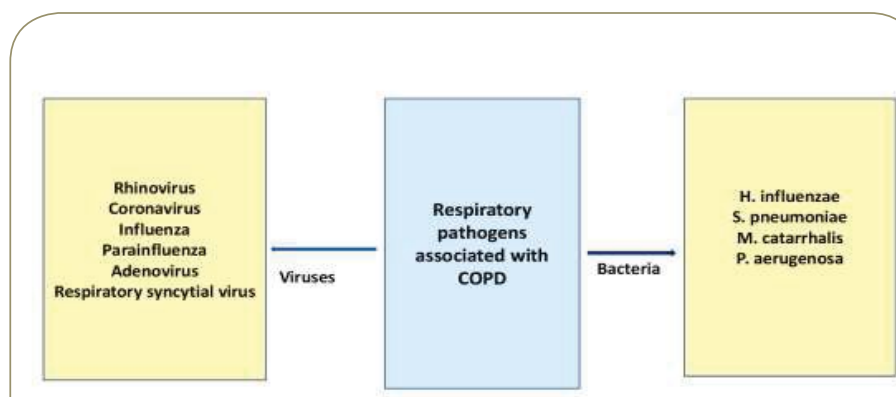

Figure 1 Common respiratory pathogens associated with COPD.

viral infections may also occur [11]. The higher frequency of occurrence of COPD exacerbations during winter season further provides the evidence for co-relation of COPD exacerbation with respiratory viral infections [12].

Most common bacterial pathogens isolated from patients with COPD exacerbations are Haemophilus influenzae, Moraxella catarrhalis, Streptococcus pneumonia, Pseudomonas aeruginosa (Figure 1) $[13,14]$. In a study conducted in 2012 in India the pattern of microorganisms during COPD was described and it was found that Klebsiella pneumoniae was the predominant organism isolated followed by Pseudomonas aeruginosa, Escherichia coli and Acinetobacter spp. It was also observed that gram negative organisms were more commonly isolated than the gram positive organisms [15].

\section{Respiratory infections}

are a major etiological factor for exacerbations. Viral infections may make the person more prone to for secondary bacterial infections which leads to the increase in the inflammation of respiratory tract and aggravates the development of the disease. Respiratory infections caused by the viruses are major concern for exacerbation. Respiratory viruses were more frequently detected during acute exacerbations of COPD in patients admitted to hospital and that CRP levels correlated with exacerbation and duration of hospital stay. It is important to identify these infections as a cause of exacerbation to avoid the unnecessary use of antibiotics. Studies have also demonstrated that a large number of patients hospitalized with COPD exacerbations suffer with concomitant viral and bacterial infections which leads to a longer duration of stay in the hospitals hospitalization were found in patients with co-infections. Preventing exacerbations is one of the main components in the management of COPD. It is well establish by various studies that respiratory tract infection is a very important factor associated with COPD exacerbations. Hence, more studies should be focused on the clinical relevance of the bacterial and viral pathogens during COPD and how the management of these pathogens should be done to prevent exacerbations and related complications and also stop the injudicious use of antibiotics. 


\section{References}

1 Morbidity and mortality: 2012 chart book on cardiovascular, lung, and blood diseases. National Institute of Health. National heart, lung and blood institute.

2 Anthonisen NR, Manfreda J, Warren CPW, Hershfield ES, Harding GKM, et al. (1987) Antibiotic therapy in exacerbations of chronic obstructive pulmonary disease. Ann Intern Med 106: 196-204.

3 Chhabra SK (2006) Asthma and Chronic Obstructive Pulmonary Disease: Are They the Same or Are They Distinct Diseases? Am J of Respir Crit Care Med 174: 1056.

4 Chhabra SK (2005) Acute bronchodilator response has limited value in differentiasting bronchial asthma from COPD. J Asthma 42: 367-72

5 Agarwal K, Sharma L, Menon B,Gaur SN (2013) Comparison in Nutritional Status in Chronic Obstructive Pulmonary Disease and Asthma. Indian Journal of Allergy, Asthma and Immunology 27: 115120.

6 Jindal SK, Aggarwal AN, Gupta D, Agarwal R, Kumar R, et al. (2012) Indian study on epidemiology of asthma, respiratory symptoms and chronic bronchitis in adults (INSEARCH). Int J Tuberc Lung Dis 16 1270-7.

7 Salvi S, Agarwal A (2012) India needs a national COPD prevention and Control program. J Assoc Physicians India 60 Suppl: 5-7.
8 Landbo C, Prescott E, Lange P, Vestbo J, Almdal TP (1999) Prognostic value of nutritional status in chronic obstructive pulmonary disease. Am J Respir Crit Care Med 160: 1856-1861.

9 Niewoehner DE, Collins D, Erbland ML (2000) Relation of FEV (1) to clinical outcomes during exacerbations of chronic obstructive pulmonary disease. Department of Veterans Affairs Cooperative Study Group. Am J Respir Crit Care Med 161: 1201-1205.

10 Donaldson GC, Seemungal T, Jeffries DJ, Wedzicha JA (1999) Effect of environmental temperature on symptoms, lung function and mortality in COPD patients. Eur Respir J 13: 844-849.

11 Menezes AMB, Victoria CG, Rigatto M (1994) Prevalence and risk factors for chronic bronchitis in Pelotas, RS, Brazil: a population based study. Thorax 49: 1217-1222

12 Donaldson GC, Seemungal T, Jeffries DJ, Wedzicha JA (1999) Effect of environmental temperature on symptoms, lung function and mortality in COPD patients. Eur Respir J 13: 844-849.

13 Sapey E, Stockley RA (2006) COPD exacerbations 2: Aetiology. Thorax $61(3): 250-258$.

14 Anto JM, Vermeire P, Vestboz J, Sunyer J (2001) Epidemiology of Chronic Obstructive Pulmonary Disease" Eur.Respir J. 17: 982-993.

15 Basu S, Mukherjee S, Samanta A (2013) Epidemiological study of bacterial microbiology in AECOPD patients of kolkata, India. Asian Journal of Pharmaceutical and Clinical Research 6: 112-116. 